\title{
Kajian Karya-Karya I Nyoman Erawan, antara Tradisi dan Modernitas
}

\author{
I Wayan Seriyoga Parta $^{1,2}$, Yustiono $^{2} \&$ Nuning Y. Damayanti ${ }^{2}$ \\ ${ }^{1}$ Jurusan Teknik Kriya, Fakultas Teknik, Universitas Negeri Gorontalo, \\ Kota Gorontalo 96128, Indonesia \\ ${ }^{2}$ KK Estetika dan Ilmu-ilmu Seni, Fakultas Seni Rupa dan Desain, Institut Teknologi \\ Bandung, Jalan Ganesa No.10, Bandung 40132, Indonesia \\ Email: yogaparta@yahoo.com
}

\begin{abstract}
Abstrak. I Nyoman Erawan adalah seniman yang mengembangkan bahasa rupa abstraksi dengan yang menggabungkan aspek-aspek formal (garis, bidang, warna dan tekstur), dengan simbol-simbol dalam tradisi budaya Bali yang berasal dari pengalaman religi yang diserapnya sebagai bagian dari masyarakat Hindu Bali. Pengalaman tersebut hadir dan memberi pengaruh pada karya-karyanya, ketika ia menempuh pendidikan seni rupa di ISI Yogyakarta pada tahun 1980 dan berkenalan dengan teknik dan wawasan seni modern. Perkembangan karya Nyoman Erawan dalam merepresentasikan nilai-nilai tradisi dan modernitas dapat dilihat dari tiga aspek yang meliputi; teknik, medium dan tema. Eksplorasi teknik dan medium Nyoman Erawan dimulai karya dua dimensi yang berwujud seni dua dimensi tahun 1982, yang menggabungkan teknik melukis dan merakit, menyusun (collage) berbagai material untuk karyanya, yang selanjutnya berkembang menjadi karya instalasi di tahun 1993-1994, dan menjadi karya performance sejak tahun 1996. Dalam karya-karyanya nilai-nilai tradisi itu mendapat ruang baru dalam interpretasi Nyoman. Meskipun dipresentasikan dengan memakai bahasa rupa seni modern Barat, nilai-nilai tradisi tersebut tetap hadir dan memberikan nuansa dalam karya-karyanya. Erawan menggunakan semangat modernitas tersebut untuk mengangkat nilai-nilai tradisi. Kondisi tersebut menjadikan perkembangan kekaryaannya, merepresentasikan perkembangan modernitas yang berbeda dengan modernitas dalam konteks di Barat.
\end{abstract}

Kata Kunci: kreativitas; medium; abstraksi; modernitas; religi; representasi; tradisi.

\begin{abstract}
I Nyoman Erawan is an artist who develops abstraction shape manner by fusing formal aspects (line, area, color and texture), with the symbols in the Balinese culture tradition which is absorbed by his own religious experience as a part of Hinduism Balinese Community. The experience exists and gives deep influence to his works, when he took art study at Indonesian Art Institute of Yogyakarta in the year of 1980 and then was introduced to modern art included to its' technique and concept. The Nyoman Erawan's works development in presenting the values of the tradition and modernity can be seen from three aspects, which includes; technique, medium and theme. The exploration of Nyoman Erawan's technique and medium was begun from two dimension
\end{abstract}

Received September $3^{\text {rd }}, 2012$, Revised October $3^{\text {rd }}, 2013$, Accepted November $29^{\text {th }}, 2013$.

Copyright () 2013 Published by LPPM ITB, ISSN: 1978-3078, DOI: 10.5614/itbj.vad.2013.5.2.4 
artworks in1982, painting technique and assemblage, collage various materials was fused for his works and then it developed become installation work in 19931994, and has become performance work since 1996. The tradition values in his work are presented in west modern art manner. He uses the modernity spirit to preserve the tradition value. He represents the development of modernity in different way than modernity in West context. This is a development of his work.

Keywords: creativity; medium; abstraction; modernity; religious; representation; tradition.

\section{$1 \quad$ Pendahuluan}

Seni Rupa Bali memiliki perkembangan yang linier dari seni rupa tradisional, kemudian terjadi transformasi dengan menyerap modernisasi dari kolonialisme Barat. Awal perkembangan ini dapat dilihat dari konteks kelahiran Pita Maha tahun 1937 yang dibentuk oleh Cokorda Gede Raka Sukawati dengan Walter Spies dan R. Bonnet. Pita Maha hadir sebagai sebuah organisasi untuk mewadahi aktivitas pelukis dan pematung Bali terutama di wilayah Ubud dan sekitarnya, serta memberikan kontribusi pada bidang pemasaran karya seni. Sebelum hadirnya Pita Maha, seniman Bali tidak memiliki kesadaran akan profesi sebagai seniman. Aktivitas melukis mereka jalani sama seperti halnya ketika mereka harus ngayah membuat gambar pewayangan langit-langit, mengukir relief pada bangunan pura dan membuat patung perwujudan DewaDewa. Spirit ngayah mendasari aktivitas seni masyarakat Bali pada umumnya. Tidak ada keterpisahan antara akivitas seni sebagai aktivitas budaya dan spiritual, namun luruh dalam satu kesatuan yang utuh [1]. Hal ini terepresentasi dalam tema-tema yang diangkat dalam seni lukis, relief maupun seni patung Bali yang pada umumnya berkisah seputar epos Mahabarata dan Ramayana, Tantri, serta cerita lainnya yang berasal dari kitab-kitab Hindu.

Kehadiran Pita Maha memberikan dampak terjadinya persinggungan pengetahuan seni rupa yang dianut oleh seniman tradisional Bali dengan pengetahuan seni rupa Barat. Hal ini terutama terlihat dalam teknik dan gaya yang dibawa oleh seniman Barat seperti; R. Bonnet dan Walter Spies. Interaksi antara nilai-nilai dalam bahasa rupa lokal dengan bahasa rupa Barat berpengaruh pada karya-karya seniman tradisional Bali. Kondisi tersebut terepresentasi dalam karya-karya para seniman Pita Maha dan turunannya terutama di wilayah Ubud dan Batuan, Sukawati [2]. Selain perkembangan seni tradisional Bali akibat dari pengaruh teknik dan gaya rupa Barat, ada sebuah alur lain juga memberi warna baru dalam perkembangan seni rupa modern Bali. Yaitu, tumbuhnya arus baru dari seniman muda Bali yang mengasah daya kreativitasnya melalui dunia akademis di perguruan tinggi seni. Sebelumnya seniman tradisional menyerap teknik, gaya, dan juga tradisi fine art, yang 
dibawa Spies dan Bonnet, diiringi dengan kebijakan kolonial dalam mengkonservasi Bali sehingga kemudian menjadi daerah pariwisata budaya. Seniman-seniman generasi akademis ini menyerap kaidah-kaidah modern, seperti; kesadaran sebagai individual, tradisi fine art (seni untuk seni), dan spirit untuk selalu mencari kebaruan dalam seni.

Penyerapan aspek-aspek dalam seni modern oleh seniman generasi akademis kemudian memberi pengaruh pada sikap dan cara berkesenian mereka sebagai seniman. Walaupun dalam perkembangan selanjutnya ide karya mereka juga menggali konsepsi dari kasanah tradisi budaya Bali yang mereka ekspresikan dalam bahasa rupa modern [3]. Akan tetapi dapat dibedakan cara dan bahasa ungkap antara seniman Bali dari tradisi Pita Maha dengan seniman dari tradisi akademis. Perbedaan ini menunjukkan adanya dua alur perkembangan seni rupa Bali yang dapat dibedakan dengan perkembangan seni rupa di daerah lainnya di Indonesia khususnya di Jawa. Perbedaan ini disebabkan karena masih adanya nilai tradisi yang terus dikembangkan pada kedua arus perkembangan dalam seni rupa Bali tersebut.

Seniman dari generasi akademis yang dimaksud, antara lain; I Nyoman Tusan, A.A. Rai Kalam, Gung Wayan Cidera yang mendapat pendidikan seni rupa di Institut Teknologi Bandung (ITB) tahun 1950 -1960. Serta para seniman muda Bali yang mendapat pendidikan dari Sekolah Tinggi Seni Rupa Indonesia (STSRI) yang kemudian menjadi Institut Seni Indonesia (ISI) Yogyakarta sejak tahun 1960-an. Mereka diantaranya adalah; Nyoman Gunarsa, Made Wianta, Wayan Sika, Pande Gede Supada, Made Djirna, Nyoman Erawan, Made Budhiana, dan masih banyak lagi lainnya yang kemudian tergabung dalam kelompok Sanggar Dewata Indonesia (SDI).

SDI merupakan sebuah wadah bagi seniman-seniman Bali lulusan ISI Yogyakarta yang dibentuk pada tahun 1970-an [4]. Para seniman muda asal Bali yang tumbuh dari medan seni Yogyakarta ini dengan sadar melakukan pembacaan ulang terhadap seni rupa Bali. Mereka mengangkat ikon-ikon Bali seperti; penari Bali yang dilukis secara ekpresif dalam karya-karya Nyoman Gunarsa, warna putih dan hitam atau poleng serta simbol-simbol seperti Swastika dalam karya-karya Wayan Sika, tulisan Bali sansekerta Made Wianta, puing-puing prosesi upacara Ngaben yang diangkat oleh I Nyoman Erawan. Ikon-ikon Bali dalam karya mereka hadir dalam pengolahan yang bersifat abstraksi. Seniman-seniman SDI selanjutnya membawa perkembangan baru bagi seni rupa Bali. Ketika mulai berkenalan dengan bahasa rupa modern melalui akademis, mereka tidak dengan serta merta meninggalkan budaya tradisi, namun justru menggali nilai-nilai tradisi budaya Bali untuk ditampilkan dalam ekspresi modern. Dalam pengantar pameran Sanggar Dewata, Millenium Art Exhibition, Bali 1999 I Made Bandem,"menekankan perlunya mengem- 
bangkan seni lukis modern yang tetap menampilkan identitas khas Bali" [5], dalam karya-karya seniman Sanggar Dewata.

Melalui karya-karya para seniman SDI, seni rupa Bali yang sebelumnya telah diperkenalkan oleh seniman generasi Pita Maha selanjutnya mengalami perkembangan lebih lanjut. Secara intensif seniman generasi SDI melakukan penggalian nilai dan spirit yang terkandung dalam entitas budaya dan seni tradisional Bali. Penggalian ini dilakukan untuk direkonstruksi dalam wujud visual yang sangat berbeda dengan karya seni rupa Bali generasi sebelumnya. Kehadiran SDI dengan kesadaran kuat mengangkat ikon-ikon budaya Bali kerap dibaca sebagai bentuk transformasi seni rupa tradisional Bali menuju seni rupa Bali modern. Menurut Hardiman; "pencapaian "baru" ini berjalan beriringan dengan situasi seni rupa modern Indonesia yang kala itu bersinggungan dengan semangat untuk melakukan penggalian identitas nasional" [6].

Sebagai bagian dari generasi seniman Bali yang berada dalam spirit SDI, I Nyoman Erawan melakukan pencarian kreativitas karyanya pada nilai-nilai tradisi religi Bali yang digali dari prosesi upacara Ngaben, yang diwujudkan dalam bahasa rupa abstrak. Selama kurun waktu dua puluh tujuh tahun (19822009) ia terus mengembangkan karya-karya dalam wujud dua dimensi, instalasi dan seni rupa pertunjukan (performance). Selanjutnya dikaitkan juga dengan konteks persoalan sosial yang melingkupi proses kreasi karyanya. Hingga akhir tahun 1990-an karya-karyanya memberi pengaruh yang cukup besar dalam perkembangan karya-karya seniman muda Bali. Sehingga Gebeh Paramartha menyebutkan banyak bermunculan "semacam epigon (penjiplak) Erawanisme" [7].

Seiring perkembangan waktu, lingkup karya Erawan tidak terbatas pada medium dua dimensi, tetapi juga berupa seni instalasi dan seni rupa pertunjukan (performance). Keragaman wujud karya tersebut memberi sumbangan dalam membuka ruang kreativitas seniman-seniman muda Bali dalam berolah unsurunsur rupa. Karya-karyanya memperlihatkan nilai-nilai kelokalan (baca: tradisi Hindu Bali) dalam ekspresi modern. Kreativitas tersebut menghantarkannya mendapatkan berbagai penghargaan, beberapa diantaranya adalah; "First Prize on 1994 The Phillip Morris Group of Companies Indonesia Art Award", Penghargaan dari Masyarakat Seni Pertunjukan Indonesia (MSPI) dalam menyambut Milenium ke-3 tahun 1999, Penghargaan Wijaya Kusuma tahun 2004 dari Pemda Kabupaten Gianyar Bali.

Perjalanan kreatif seorang seniman, dalam hal ini Nyoman Erawan yang secara terus-menerus mengangkat nilai-nilai tradisi religi budaya Bali dalam penciptaan karyanya sejak tahun 1982-2009, sangat menarik untuk ditelusuri. Aktivitas seni yang dijalaninya tidak hanya berhubungan dengan proses 
produksi benda-benda kreatif yang disebut karya seni semata, namun juga berhubungan dengan cara pandang seniman melihat realitas dan menampilkan pengalaman tentang realitas tersebut secara visual dalam karyanya. Dalam konteks ini terjadi pencerapan, penafsiran dan interpretasi yang kemudian ditransformasikan menjadi wujud visual dengan medium-medium seni, seperti; lukisan, patung, musik, suara, gerak dan lainnya. Selain itu, latar belakang budaya yang melingkupi seniman, yang juga memberi pengaruh pada proses kreativitasnya dalam berkarya. Sebagai seorang seniman yang telah melakukan eksplorasi pada berbagai medium, Erawan mengalami kompleksitas dari proses kreasi tersebut. Ia yang tumbuh dalam budaya Bali, sejak kecil telah berkenalan dengan kesenian, seni menggambar, mengukir, menabuh gamelan Bali, hingga tari. Kesenian itu ia geluti dalam sebuah entitas budaya yang menjadi bagian integral dalam kehidupan masyarakat Bali. Kosmologi religi Bali memberi pengaruh bagi proses kreativitas berkeseniannya yang ditempa lebih lanjut melalui pendidikan seni dari ISI Yogyakarta.

Pembahasan ini mengkaji sosok Nyoman Erawan dan karyanya, dalam kerangka persoalan; nilai tradisi dan modernitas yang mengiringi proses kreativitasnya. Dua nilai tersebut juga merupakan persoalan yang masih menjadi pembahasan dalam memetakan dan mengkaji modernitas pada seni rupa Bali dan secara langsung berkaitan juga sebagai bagian dari perkembangan modernitas dalam seni rupa Indonesia. Karya-karyanya yang akan diuraikan adalah karya-karya yang dikerjakan selama kurun waktu tahun 1982 hingga tahun 2009. Selama dua puluh tujuh tahun ia telah menjalani perjalanan kreatif dalam wilayah kreatif yang cukup luas, meliputi karya-karya seni lukis, karya instalasi dan seni rupa pertunjukan (performance), yang secara konsepsi digali dari nilai-nilai religi budaya Bali.

\subsection{Metodologi}

Penelitian ini menggunakan metode kualitatif, dengan menyajikan kajian interaksi dua nilai yaitu nilai tradisional dan nilai modernitas dalam kekaryaan I Nyoman Erawan secara deskriptif. Kedua nilai tersebut akan dilihat dalam karya-karya I Nyoman Erawan sepanjang tahun 1982-2009, serta mengkaji aspek-aspek tradisi dan modenitas yang berperan dalam mempengaruhi proses kreativitasnya. Kajian ini bersifat interdisiplin, dengan melibatkan beberapa pendekatan keilmuan antara lain; sejarah seni dalam mengkaji perkembangan seni rupa Bali yang menjadi medan seni bagi eksistendi Nyoman Erawan. Pendekatan kajian budaya untuk mengkaji latar budaya Bali yang mempengaruhi perkembangan seni rupa Bali dan proses kreativitas Nyoman Erawan. Pendekatan kritik seni untuk menganalisis karya-karya Erawan yang merepresentasikan nilai tradisi dan modernitas. 
Gambar 1 berikut ini adalah skema analisis data dalam penelitian ini.

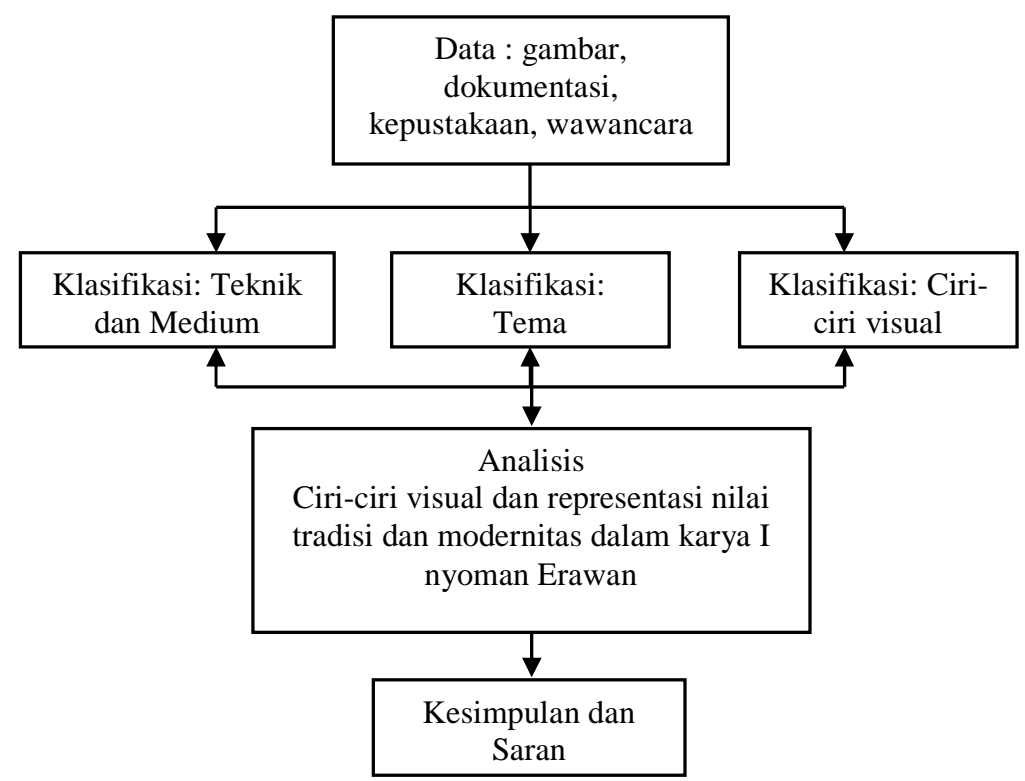

Gambar 1 Skema Analisis Data [8].

\section{Pembahasan}

Nyoman Erawan yang lahir tahun 1958 di Banjar Delodtangluk, Sukawati, Gianyar Bali, adalah seniman yang tumbuh dalam keluarga dan lingkungan masyarakat yang memegang teguh adat-istiadat dan budaya tradisi yang berakar dari nilai-nilai Hindu Bali. Bapaknya pernah menjabat sebagai pamong desa dan juga pematung. Ibunya adalah seorang tukang banten (orang yang mahir membuat sesajen). Sejak kecil ia sudah terbiasa memahat patung atau membuat ukiran. Bakat seninya tumbuh dari lingkungan Sukawati yang dikenal sebagai salah satu daerah pusat sentra dan juga pasar seni kerajinan di Bali. Dalam perjalanan waktu, bakat tersebut dengan sadar terus ia asah melalui pendidikan formal dari Sekolah Menengah Seni Rupa (SMSR) Denpasar, kemudian dilanjutkan ke Institut Seni Indonesia (ISI) Yogyakarta (tahun 1981-1987). Melalui lembaga formal itulah, "I Nyoman Erawan mulai mengenal seni rupa sebagai media yang memperantarai hubungan pemahaman makna antara bahasa rupa Bali yang ia miliki dengan seni rupa yang ia pelajari" [9]. Ia menyerap kaidah-kaidah formal, teknik, serta bahasa rupa modern yang kemudian mendasari perjalanan kreativitas dalam penciptaan karya-karyanya. Perkenalannya dengan kaidah-kaidah seni rupa modern dari lembaga pendidikan ISI Yogyakarta berpengaruh besar bagimya dalam memahami seni 
rupa. Kaidah-kaidah seni modern yang diserapnya melalui bangku akademis, dipadukan dengan nilai-nilai dalam tradisi yang sejak kecil dia jalani dalam kehidupan sosial budaya di Bali.

Pencarian identitas seni rupa Indonesia menjadi wacana penting ketika Erawan memasuki pendidikan akademis di ISI Yogyakarta pada awal tahun 1980. Kondisi tersebut menjadikannya sampai pada pencarian kreatif yang digali dari prosesi dalam upacara Ngaben di Bali. Sebagai anggota banjar, ia selalu terlibat dan bahkan memegang posisi penting dalam pelaksanaan upacara-upacara seperti Ngaben, mecaru, atau terlibat dalam upacara-upacara besar di Desa atau Banjar kelahirannya di Sukawati. Dalam sebuah wawancara ia menuturkan: "sosialisasi saya di banjar adalah juga sebuah proses berkesenian. Saya berdialog begitu intim dengan tradisi itu. Ketika saya mengerjakan lembu atau meraut katik (tusuk sate) itu betul-betul saya hayati. Dan ini akan sangat berguna sebagai pembentuk spirit dalam karya-karya saya" [10]. Dapat dikatakan, pengalaman kultural itu memang memberikan kontribusi dalam perjalanan keseniannya. Setelah selesai dari menempuh pendidikan seni rupa di ISI Yogyakarta, ia memilih tidak menetap di Yogyakarta tapi pulang ke Bali. Sebagai bagian dari masyarakat adat, ia selalu terlibat dalam kegiatan upacara baik Dewa Yadnya, Manusia Yadnya, ataupun Butha Yadnya. Keterlibatannya bukan hanya sebagai anggota masyarakat biasa. Ia kerap kali ditunjuk oleh masyarakat untuk menjadi ketua pantia karye (upacara).

\subsection{Representasi Nilai Tradisi dan Modernitas dalam Karya Nyoman Erawan}

Nyoman Erawan tumbuh sebagai seniman Bali dari generasi yang menyerap wawasan seni rupa modern dari pendidikan ISI Yogyakarta. Meskipun metode penciptaan di ISI Yogyakarta cenderung tidak semendalam seperti di ITB dalam menyerap kaidah-kaidah seni rupa Barat (modern-kontemporer), minimal para mahasiswa ISI Yogyakarta mendapat wawasan tentang karya-karya seni modern. Wawasan itu membuat para mahasiswa seperti Erawan yang telah memiki dasar seni rupa tradisional Bali, mulai menyerap penciptaan seni rupa Barat terutama dalam teknik, medium (seni lukis, instalasi dan performance), gaya dan juga kesadaran sebagai seniman individual. Identifikasi karya-karya dalam Tabel 1 menunjukkan eksplorasi estetis karya-karyanya terus berkembang seiring dengan perjalanan waktu, dari karya dua dimensi menjadi instalasi (dua dan tiga dimensi) hingga pada karya performance art.

Bermula dari mengolah elemen visual dalam bidang dua dimensi dengan teknik melukis dan menempel (mengkolase). Berkembang menjadi mengkomposisi dengan menginstal berbagai material sebagai elemen-elemen rupa dalam karya- 
Tabel 1 Perkembangan Medium Dalam Karya Nyoman Erawan [8].

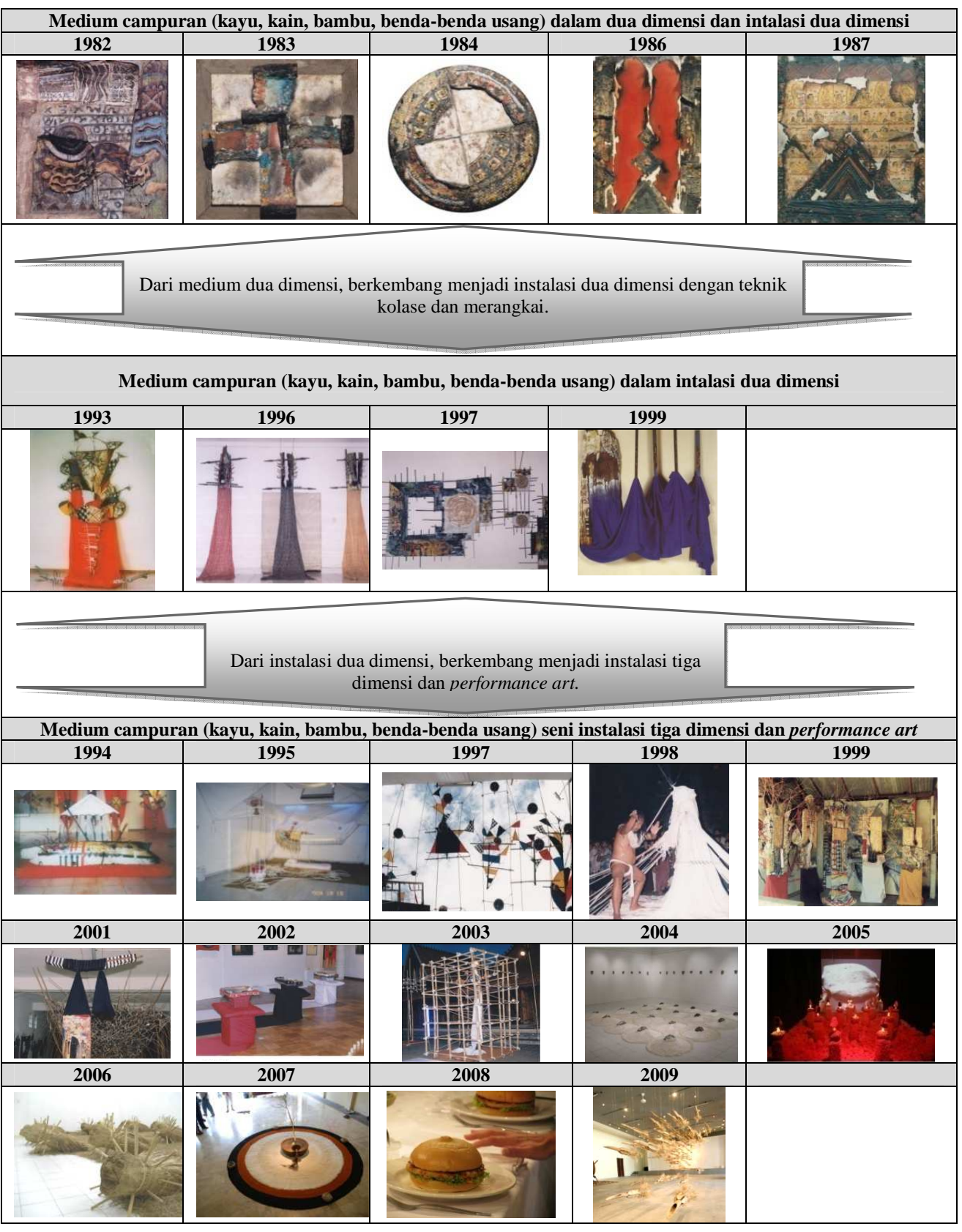


karya instalasi, untuk selanjutnya berkembang ke seni rupa pertunjukan (performance art) dengan memakai material dan teknik yang lebih kompleks. Perkembangan ini dipengaruhi oleh wawasan seni rupa Barat yang didapatkannya dari buku-buku dalam pendidikan seni rupa. Wawasan seni rupa modern yang diserapnya melalui pendidikan formal, tentang tradisi fine art, dan semangat avant garde, dalam mengejar berbagai penemuan baru. Hingga fenomena intermedia, seperti; kolase, assemblase, seni instalasi, yang diwujudkan dari barang-barang temuan atau ready made, action painting, hingga berkembang menjadi performance art, happening art, projek-projek seni lingkungan (enviromental art), dan seni lintas batas lainnya. Pengetahuan itu memberi pengayaan bagi perkembangan kekaryaan Erawan, yang lintas medium.

Dalam karya-karya yang memakai berbagai material menunjukkan bahwa wawasan seni rupa Barat itu juga memberi pengaruh pada perluasan eksplorasi yang lintas medium. Selain mendapat dari wawasan seni rupa modern, eksplorasi itu juga dipengaruhi pengalaman kultural dari menjalani tradisi Hindu di Bali, yang di dalamnya melibatkan aktivitas merangkai (menginstal) banten (yadnya) dengan berbagai material. Pengalaman itu berperan dalam memberikan pengalaman teknik dalam proses perwujudan karyanya, terutama dari cara menggabungkan komponen-komponen visual, serta simbol-simbol religi yang sengaja ia ketengahkan sebagai konten karya. Kedua aspek ini bertemu, dan menumbuhkan kreativitasnya dalam mengeksplorasi gagasan kreatif dengan memanfaatkan berbagai material dan lintas medium. Secara visual eksplorasi tersebut dimaksudkan untuk menampilkan kontens yang berkaitan dengan nilai-nilai spiritualitas ataupun kegelisahannya tentang fenomena sosial.

Selain pada pengembangan medium, Erawan juga memiliki keterikatan yang erat dengan tradisi budaya Bali dan mejadikan nilai-nilai tradisi tersebut sebagai pijakan dalam eksplorasi estetiknya. Nilai-nilai tradisi tersebut, akan dijabarkan pada pembahasan berikut; pada karya-karya awal ia banyak menggunakan api atau pembakaran pada material karya, berkaitan dengan konsep berkarya yang terinspirasi oleh prosesi kremasi (pembakaran mayat) dalam tradisi ngaben di Bali (lihat Gambar 2).

Ngaben merupakan proses peleburan antara zat-zat mikrokosmos yang ada dalam diri manusia antara lain unsur Panca Maha Bhuta seperti; apah (air), teja (api), pertiwi (zat padat), bayu (angin), dan akasa (ruang), untuk dikembalikan dan menyatu kembali dalam kesemestaan alam makro kosmos. Proses penghancuran dan penyatuan inilah yang menginspirasi konsep karyanya yang direpresentasikan dengan bidang-bidang terbakar tersebut. 

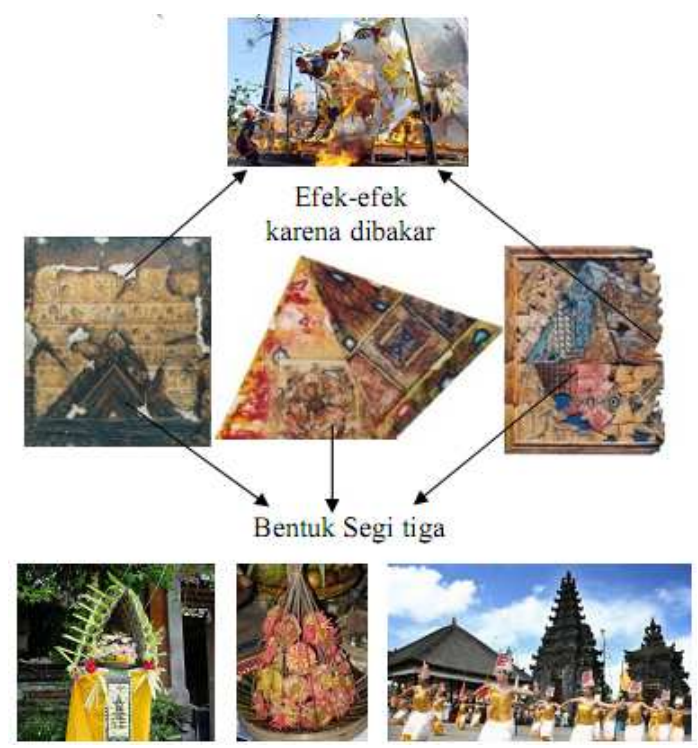

Gambar 2 Prosesi Bidang Segi tiga dan efek-efek karena pembakaran dalam karya-karya Nyoman Erawan [8].

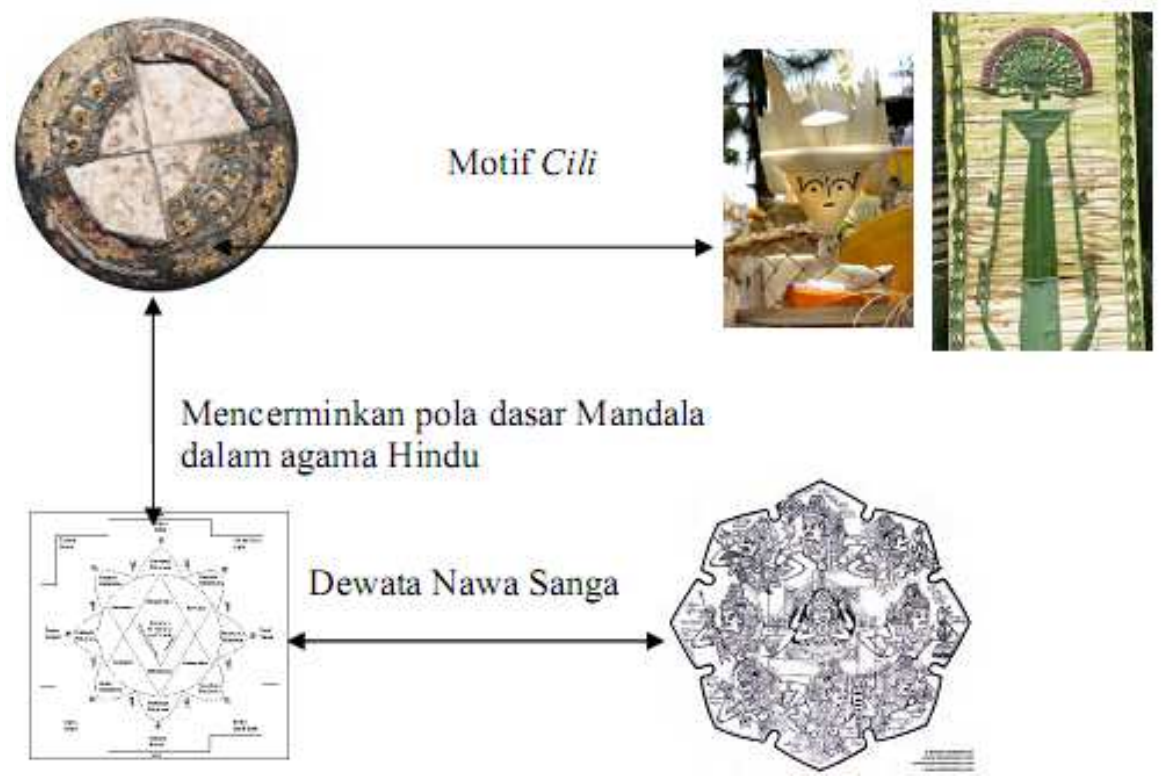

Gambar 3 Motif geometris yang mengambar Cili, dan pola Mandala dalam karya Nyoman Erawan [8]. 
Dalam kepercayaan Hindu khususnya di Bali bentuk segi tiga memiliki nilai filosofi yang sangat dalam, melambangkan Gunung yang menjadi salah satu arah kiblat selain arah Matahari. Merupakan representasi posisi tangan dalam persembahyangan (muspa), menjadi pola pada struktur bangunan pura mulai dari motif-motif ornamen, bentuk gapura, atap bangunan pelinggih, serta dalam berbagai bentuk-bentuk yadnya atau sesajen. Segi tiga dalam bentuk Tri Sula, melambangkan senjata Dewa Wisnu, disebut juga dengan istilah yantra, segi tiga yang berpadu. Bentuk segi tiga juga hadir dalam wujud yang disebut cili, yang melambangkan dewa-dewi, yang banyak dipakai dalam sesajen. Dalam karya Bidang Rusak I 1984 (skema II), menghadirkan motif Cili, dan pola Mandala dalam struktur karya yang berbentuk lingkaran (lihat Gambar 3).

Mandala yang sering disebut Mandala Siwa dalam agama Hindu di Bali lebih sebagai Dewata Nawa Sanga menampilkan komposisi sembilan Dewa di penjuru mata angin dengan Siwa sebagai pusat dan berada di tengah. Dalam kreativitas seniman tradisional Bali penggambarannya banyak mengalami penggayaan yang difokuskan pada penggambaran dewa-dewa dan atributnya, sehingga struktur garis atau bidangnya kadang kala tidak ditampilkan. Bentuk dan pola-pola yang terdapat dalam kasanah kosa rupa religi Hindu Bali diadopsi oleh Erawan guna menjadi elemen rupa dalam pengolahan estetik dalam karyanya.

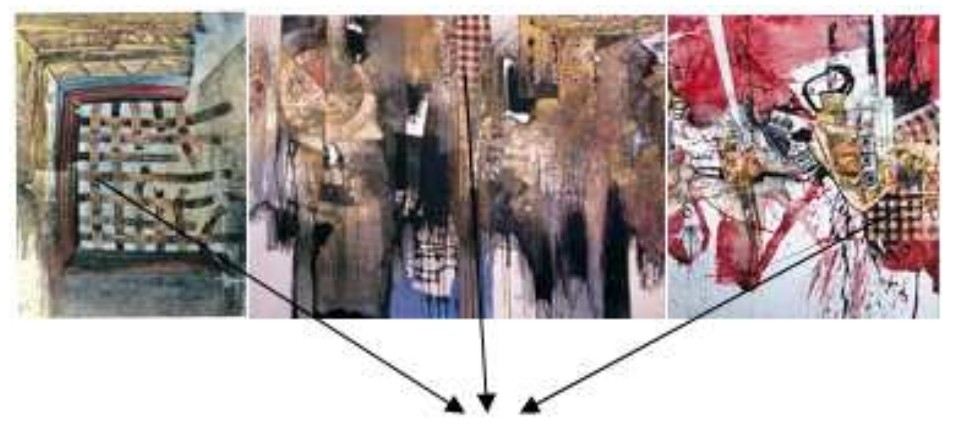

Motif Poleng

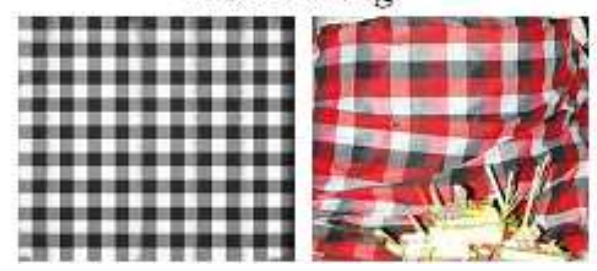

Gambar 4 Motif poleng banyak dipakai dalam karya Nyoman Erawan [8]. 
Pola yang juga kerap kali dipakai oleh Nyoman Erawan adalah poleng berupa pola persegi yang bersusun dengan warna hitam putih (lihat Gambar 4), ᄀabuabu atau warna hitam, putih, merah yang melambangkan warna Tri Datu. Poleng dalam kepercayaan Hindu Bali merupakan perlambangan rwa bhineda nilai kebaikan dan kejahatan (jele dan melah) juga ada warna abu-abu yang menandakan selain kedua nilai tersebut juga ada wilayah antara (in between). Di Bali istilah lanang (lingga) disebut juga purusa, wadon (yoni) disebut sebagai predana, selain dua itu dikenal juga wadu merupakan posisi yang berada di tengah dalam posisi gender sering disebut dengan fenomena transeksual, dan dikatakan dalam ajaran Hindu semua itu diciptaan oleh Hyang Widhi Wasa (Tuhan).

\section{Komparasi 1}
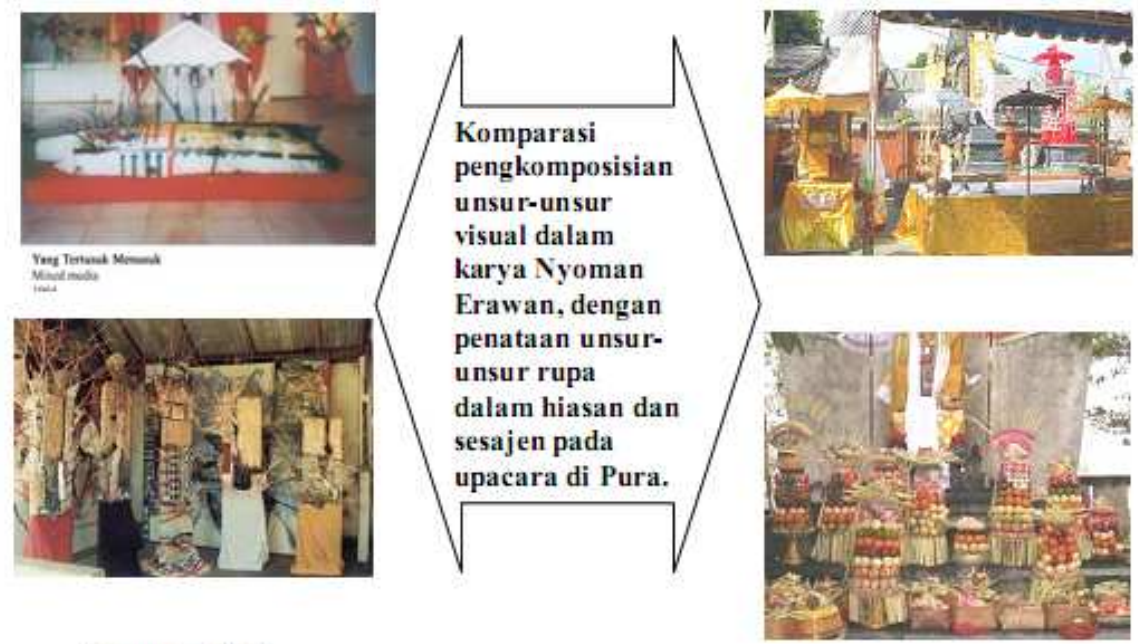

Komparasi 2

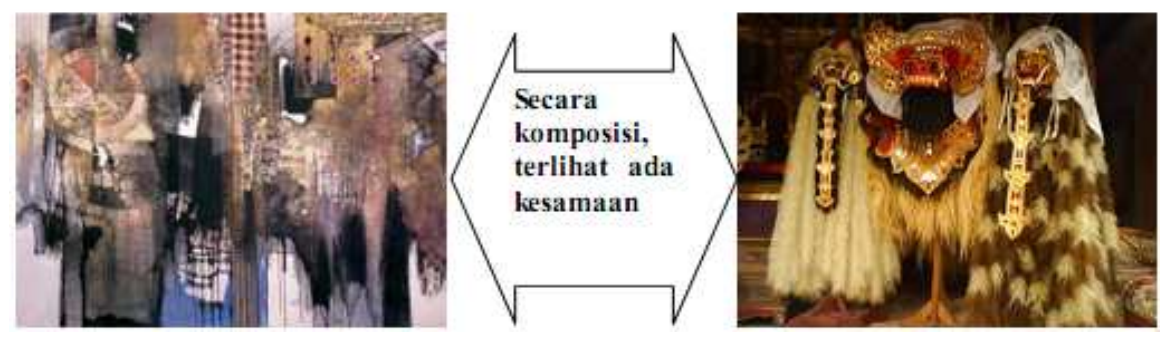

Gambar 5 Kencederungan komposisi dalam Karya Erawan yang diilhami oleh komposisi dalan tradisi religi Hindu Bali [8]. 
Selain menampilkan warna poleng karya Erawan juga banyak menampilkan komposisi warna Tri Datu, berupa warna merah, hitam, putih. Tri Datu, melambangkan tiga Dewa (Tri Murti), antara lain; Brahma warna merah, Wisnu warna hitam dan Iswara/Siwa warna putih. Penekanan terhadap hal ini diberikan dengan penjudulan karya seperti; Tri Datu Angin 2000 dan Tri Datu Bumi 2001, penjudulan tersebut menunjukkan intensitas dalam menterjemahkan filosofi Hindu Bali ke dalam karyanya. Keterkaitan dengan kosa rupa Bali juga dapat dilihat secara komposisi unsur-unsur rupa. Karya instalasi berjudul Yang Tertusuk Menusuk 1994 dan Kalpataru II 1999, memperlihatkan kencederungan komposisi elemen-elemen visual yang identik dengan penataan sesajen dalam upacara yadnya di Bali (dua karya pada posisi kiri atas dalam Gambar 5).

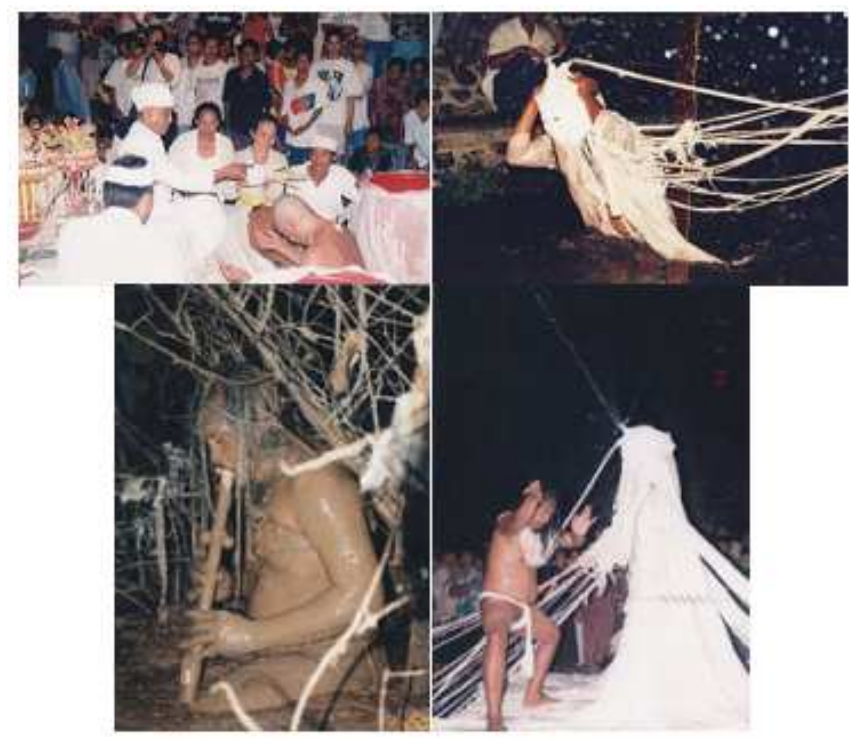

Gambar 6 Erawan sedang diruat (dibayuh) dengan upacara Hindu [8].

Kecenderungannya juga dapat dilihat dalam karya Mandala Fissure 1995 (karya posisi kiri bawah dalam skema IV), yang komposisinya menampilkan kesamaan dengan penempatan Barong dan Rangda di Pura. Warna poleng pada karya ini ditempatkan pada posisi tengah dan mandala terletak di kiri dan bagian kanan diseimbangkan dengan komposisi warna yang senada, karya ini menampilkan kesimbangan yang formal. Mode pengkomposisian itu menandakan kreativitas kekaryaan Erawan juga mendapat pengaruh dari latar belakang kehidupan keagamaan yang dijalaninya. Berupa pengalaman ketika ia kerap terlibat dalam pembuatan upakara (sesajen) untuk upacara yadnya. 
Manusia Bali pada umumnya telah diupacarai sejak lahir; mulai dari umur satu bulan tujuh hari, tiga bulan, upacara otonan yang rutin setiap enam bulan selama hidup, upacara menjelang remaja, upacara potong gigi (metatah), perkawinan, hingga kematian seluruh hidupnya diiringi dengan upacara dan upakara (banten). Dalam prosesi upacara yang berupa upakara tersebut melibatkan simbol-simbol yang diterjemahkan dalam rangkaian banten (sesajen), diwujudkan dari berbagai elemen alam seperti; daun, kayu/bambu, bunga, daging hewan, yang diolah dan dirangkai sedemikian rupa menjadi karya seni rupa, seni kriya, seni suara (mantra, kidung, dan tabuh/musik) dan seni tari (Gambar 6).

Pengalaman itu tidak hanya ditransformasikan dalam wujud visual dua dimensi, lebih jauh Erawan juga melibatkan upacara yadnya ke dalam karya performance nya. Hal ini dapat dilihat dalam karya performance art yang berjudul Ruatan 1998 yang memasukkan secara langsung prosesi upacara menjadi bagian dari rangkaian karyanya. Performance art Ruatan memakai sarana upacara yang dihantarkan (dipuput) oleh seorang pemangku, prosesi ruatan dimaksudkan untuk memberikan atau menyucikan diri secara niskala. Karya ini merupakan kasus menarik dalam seni rupa Bali, karena keberanian seorang seniman Bali dalam memasukkan upacara yadnya dalam karya performance-nya yang dalam hal ini lebih bersifat profan. Sebuah fenomena menarik, ternyata dari kreasi performance art Ruatan 1998 itu justru tidak mendapat reaksi negatif dari sebagian besar umat Hindu Bali. Dalam kehidupan sosial kreativitas Erawan justru diapresasi sebagai seniman modern Bali, dengan berbagai eksplorasi karya yang di dalamnya juga tetap menampilkan konten yang berhubungan dengan nilai-nilai tradisi khususnya religi Hindu Bali.

Melalui karya performance art-nya, Erawan mengeksplorasi tubuh sebagai manifestasi dari buana alit (mikrokosmos) yang perlu diruat dalam hubungannya dengan buana agung (makrokosmos). Kehadiran tubuh sebagai subject matter merepresentasikan sebuah perjalanan dalam mengesplorasi konsep mengenai hubungan mikro kosmos dan makro kosmos yang dimulai dari karya-karya yang menampilkan representasi ngaben. Bermula dari tematema yang kental dengan muatan religi dan bersifat hubungan vertikal (spiritual), kemudian bergerak pada tema bermuatan horisontal persoalanpersoalan yang tengah dirasakan sebagai bagian dari kehidupan sosial masyarakat. Hal ini terutama dipresentasikan dalam karya-karya performance seperti karya Ruatan Bumi 1998, Sikat Gigi 2001, yang merepresentasikan konteks persoalan sosial. Kecenderungan eksplorasi tubuh dalam karya Erawan dapat dilihat pada Tabel 2. Data pada tabel tersebut menunjukkan kehadiran figur menjadi salah satu kecenderungan subject matter karya seni lukis, instalasi, figur atau tubuh menjadi medium utama dalam performance art (Tabel 2). 
Tabel 2 Eksplorasi tubuh dalam karya Nyoman Erawan [8].

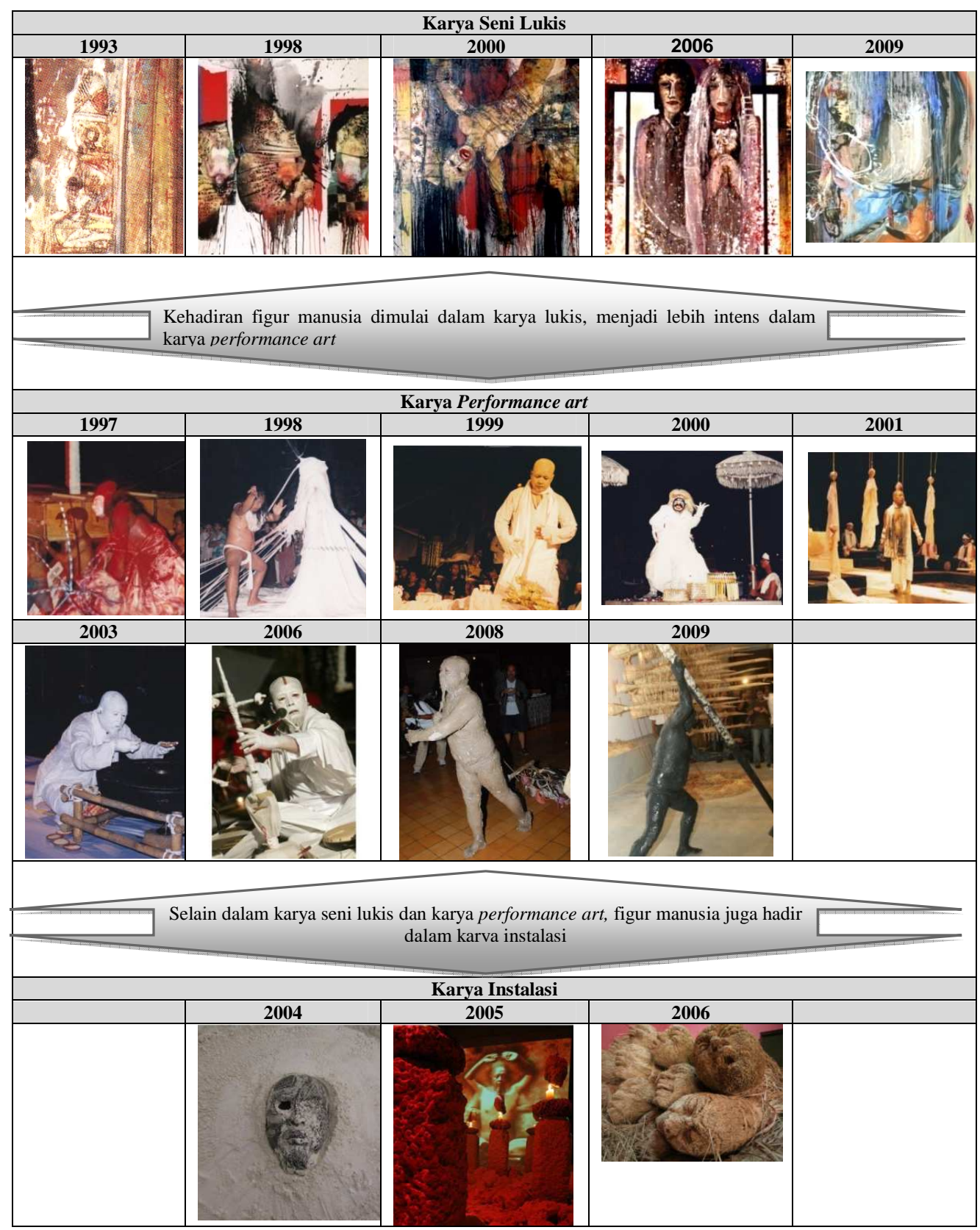


Tabel 3 Perkembangan mimik wajah dalam karya Nyoman Erawan [8].

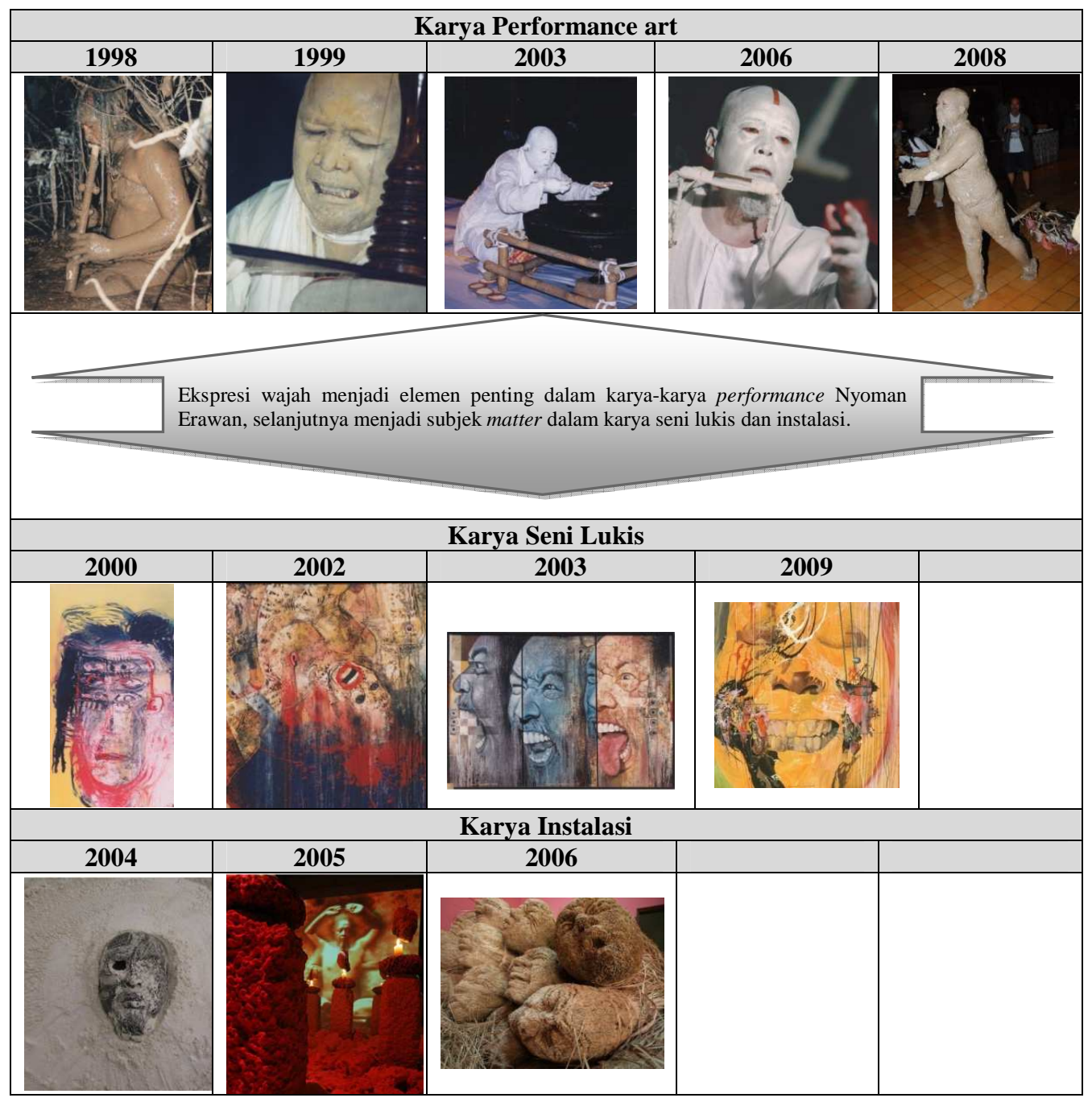

Dalam perkembangan eskplorasi tubuh, untuk karya dua dimensi Erawan terlihat lebih mengkhususkan pada ekspresi wajah. Wajah dalam karya instalasi dan karya seni lukis tersebut tidak lain bersumber dari karya performance art, hal ini dapat ditengarai dari kehadiran wajah dengan ekspresi dan mimik wajah yang dilumuri cat atau tanah. Ekspresi mimik wajah yang pada awalnya hadir dalam karya performance art, direpresentasikan kembali ke bidang kanvas, dengan material resin, dan alang-alang (Tabel 3). 
Perkembangan karya-karya yang berangka tahun 2009 menampilkan fenomena apropriasi, dimana wajah digabungkan dengan elemen-elemen yang diambil elemen-elemen rupa dalam karyanya. Antara lain seperti: kecenderungan bendabenda yang digantung dengan tali, benda seperti jarum yang tertusuk dan goresan kuas kasar, cipratan dan lelehan warna yang ekspresif digabungkan kembali dalam representasi baru. Rekonstruksi visual itu bertujuan untuk mencari pemaknaan baru tentang konsep yang berkaitan dengan relasi hubungan alam mikro dan makro kosmos yang secara menerus dipersoalkan.

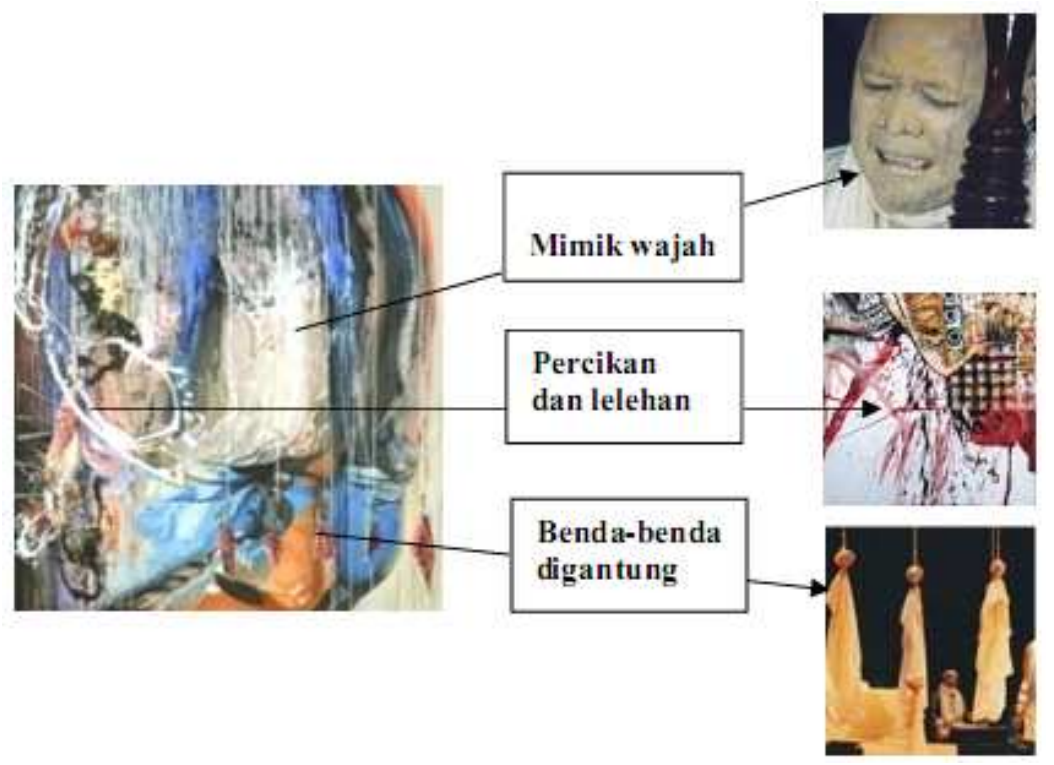

Gambar 7 Fenomena apropriasi dalam karya Erawan tahun 2009 [8].

Gestur dan mimik wajah dipakai untuk menampilkan narasi tentang kondisi "depresi" seperti digambarkan dalam judul karya, digabungkan dengan elemen lain seperti batu, daun, daging, pancing, dan tali. Relasi pemaknaan antar elemen tersebut dibangun dari unsur-unsur visual yang diambil dari karyanya terdahulu, yang dikomposisi ulang dalam karya baru, tema baru dan pemaknaan yang baru. Eskplorasi visual tersebut menunjukkan kini Erawan telah sampai pada kecenderungan apropriasi [11], dengan mengarahkan perhatian untuk melihat ke dalam rentang perjalanan kekaryaannya selama 27 tahun, ada semacam evaluasi diri dan evaluasi kreativitas yang sedang dia dilakukan. Hal ini tercermin dari eksplorasi visual dalam karyanya, yang kembali menggali unsur-unsur dari kasanah rupa yang telah dikerjakannya selama ini (Gambar 7). 
Setelah sekian lama mengeksplorasi ikon dan symbol religi untuk direkonstruksi dalam karya, kini ia menghentikan proses itu dengan lebih memilih untuk merekonstruksi (mendaur ulang) kembali unsur-unsur visual yang telah menjadi "identitas" karyanya. Sebagai elemen visual yang berfungsi sekaligus juga sebagai metafor, untuk mengetengahkan kegelisahannya sebagai perupa dan bagian dari entitas sosial dan budaya di masyarakat.

Tabel 4 Kecenderungan pemakaian komposisi warna Tri Datu dalam karya Nyoman Erawan [8].

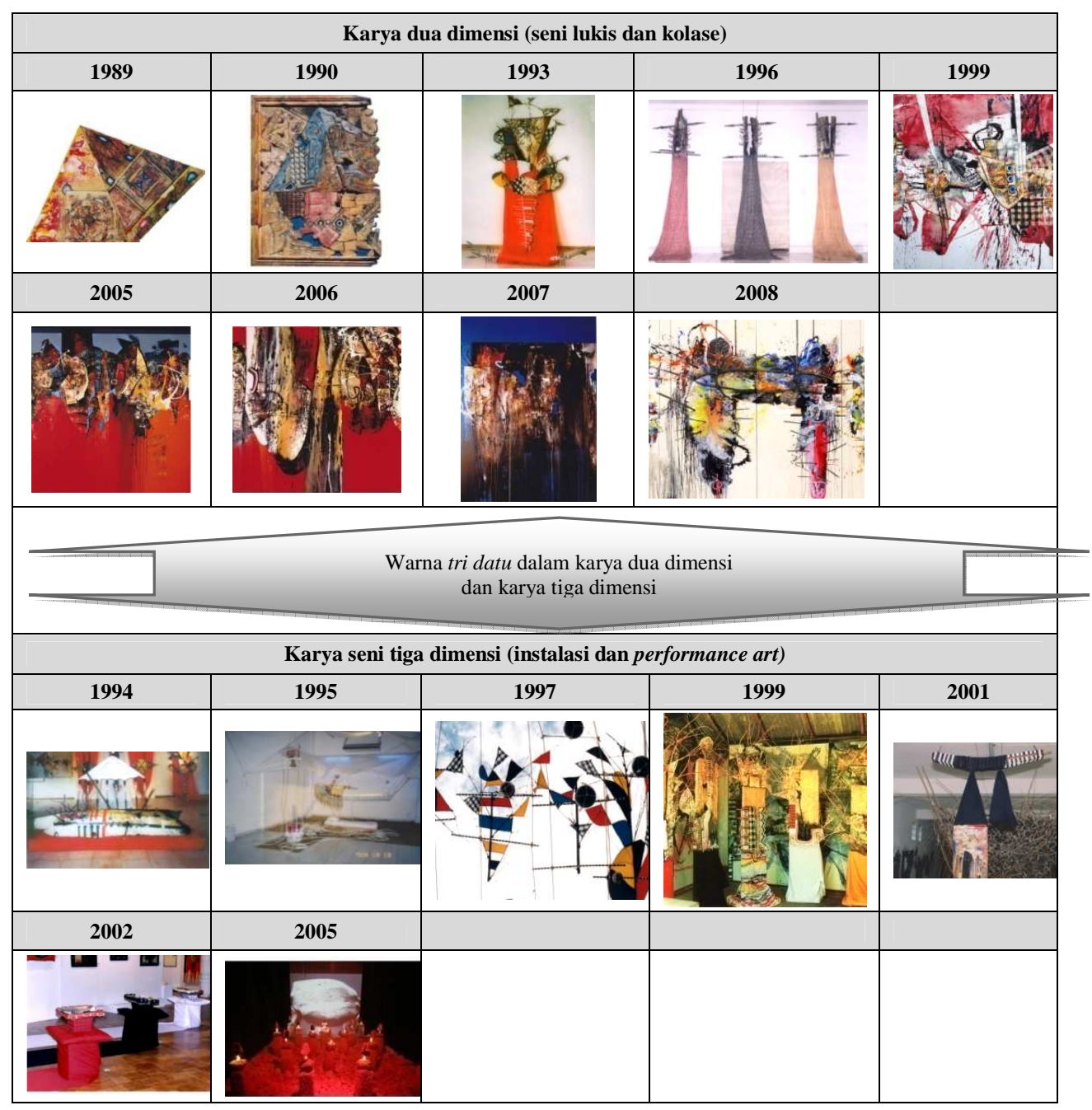


Selain dapat dikaji dalam unsur-unsur visual, nilai-nilai tradisi religi juga dapat dilihat dari penggunaan judul dengan istilah-istilah seperti: Puing Ngaben (1982-1984), Bidang Rusak (1984-1986), Imaji Bali Kuno dan Kekunoan (1987-1991), Tanpa Yantra (basis energi alam)1989, Pralaya Matra (19961998), Reinkarnasi (1997-1998), Tri Datu 2000-2003. Judul-judul tersebut, memperlihatkan sebuah usaha untuk membuat penjangkaran pemaknaan dalam menampilkan nilai-nilai religi Hindu pada karya-karyanya yang secara kasat mata menampilkan abstraksi. Nilai religi tersebut ditampilkan melalui kehadiran ikon dan simbol-simbol seperti; warna Tri Datu, terdiri dari; merah, hitam, putih, merupakan warna-warna menyimbolkan dewa Tri Murti (tabel 4). Lambang-lambang seperti tampak dara (+), warna poleng (hitam-putih), motif ukiran, dan unsur-unsur visual tersebut dipresentasikan dalam karya seni dua dimensi, hingga karya instalasi dan performance.

Ketika Erawan memasuki pendidikan seni rupa di ISI Yogyakarta pada tahun 1980 dan berkenalan dengan teknik dan wawasan seni modern, pengalaman kultural hadir dan memberi pengaruh karya-karyanya.

Berdasarkan kajian terhadap karya-karya Erawan, perkembangan representasi nilai-nilai tradisi dan modernitas yang menjadi topik sentral kajian, dapat dilihat dari aspek bentuk dan isi (konten), aspek bentuk meliputi; penyusunan elemenelemen visual yang diwujdkan dengan penguasaan teknik dan medium, dan aspek kontens yang terelaborasi dalam tema karya. Nilai kontens sendiri berhubungan dengan representasi konsep dan pemikiran sang senimannya. Perkembangan ini, sekali lagi berhubungan dengan latar belakang budaya yang dijalaninya sebagai bagian dari masyarakat adat Bali. Dimana ia selalu terlibat di dalam penyelenggaraan upacara keagamaan, proses menjadikannya memiliki pengetahuan upacara dan kandungan makna-makna filosofis di dalamnya. Untuk selanjutnya pengetahuan dan pengalaman tersebut berperanan besar dan bersifat aplikatif pada proses kreativitas penciptaan karyanya.

\section{$3 \quad$ Penutup}

Bersadarkan pengamatan dan pengkajian terhadap karya-karya Nyoman Erawan, dapat dirumuskan bahwa kedua nilai yaitu; nilai tradisional dan modern berjalan beriringan dalam proses kreativitasnya. Kondisi ini yang membedakan karya-karyanya dengan seni modern di Barat (modernisme), yang menampikkan tradisi dan nilai-nilainya karena dianggap tidak sesuai dengan semangat zaman dan pencarian kebaruan [12]. Namun tidak halnya bagi Erawan, penjajaran elemen tradisi dan modern merupakan kondisi yang tengah dijalaninya, modernitas dengan kemajuannya tidak harus melupakan atau meninggalkan masa lalu. Justru sebaliknya masa lalu baginya tetap dapat menjadi sumber dan inspirasi bagi penciptaan-penciptaan baru. Pengalaman 
kultural dalam merangkai berbagai bentuk-bentuk sesajen memberikannya kepekaan dalam mengkomposisikan unsur-unsur rupa dan berbagai material dalam karyanya. Kreativitas yang dijalani Erawan dalam berkarya menampilkan fenomena modernitas yang berbeda dengan modernitas seni rupa modern Barat [13], yang mana nilai tradisi justru dikemas dengan bahasa rupa modern yaitu gaya abstraksi. Sebuah penyatuan yang dalam paradigma modern bersifat kontradiktif namun justru penuh harmoni di tangan Erawan, pencapaian estetiknya menghantarkan ia pada sosok seniman modern Bali dan bahkan Indonesia yang merepresentasikan kekhasan kondisi modernitas.

\section{Referensi}

[1] Picard, M. 2006. Bali: Pariwisata Budaya dan Budaya Pariwisata, diterjamahkan oleh: Jean Couteau dan Warih Wisatsana, KPG, hal. 22.

[2] Merta, D.P. 2007. Seni Lukis Bali dari Perspektif Modernisasi, Jurnal Seni Budaya Mudra, 20(1), ISI Denpasar

[3] Couteau, J. 2003. Wacana Seni Rupa Bali Modern, ASPEK-ASPEK VISUAL ART, Yayasan Seni Cemeti Yogyakarta, hal. 102, (Editor Mikke Susanto).

[4] Wiyasa, I M.B. 2005. Sejarah Sanggar Deawata Indonesia, Skripsi S-1, Program Studi Seni Rupa Murni, Jurusan Seni Murni, Fakultas Seni Rupa, Institut Seni Indonesia Yogyakarta.

[5] Bandem, I M. 1999. Katalog pameran Sanggar Dewata, Millenium Art Exhibition, Bali.

[6] Hardiman. 2008. Dua Dialek Seni Rupa Bali, Majalah Seni Rupa Visual Art, 5, Jakarta

[7] Pramarta, G. 2000. Epigonisme Nyoman Erawan, Tabloid Detak, hal. 98.

[8] Parta, I W.S. 2010. Kajian Karya Nyoman Erawan, Antara Tradisi dan Modernitas, Bandung: Program Magiter Seni Rupa, Institut Teknologi Bandung.

[9] Mamannor. 2003. PRALAYA; Prosesi Kehancuran dan Kebangkitan. Katalog Pameran Tunggal I Nyoman Erawan, Bentara Budaya Jakarta

[10] Arcana, P.F. \& Erawan, N. 1997. Bali dan Seni Masa Kini, Kompas, 20 Mei 1997.

[11] Young, J.O. 2008. Cultural Appropriation and the Arts, Blackwell Publishing USA, UK.

[12] Irianto, A.J. 2000. Konteks Tradisi dan Sosial Politik Dalam Seni Rupa Kontemporer Yogyakarta Era '90-an, Outlet; Yogya Dalam Peta Seni Rupa Kontemporer Indonesia, Yayasan Seni Cemeti Yogyakarta, hal. 77.

[13] Supangkat, J. 2003. Art with Accent, Katalog Pameran CP, Open Biennale I Jakarta, hal. 51. 